\title{
Joseph A. Prahlow, Roger W. Byard: Atlas of forensic pathology
}

\author{
Springer Science + Business Media, New York, 2012, 906 pp, \\ Hardback ISBN 978-1-61779-057-7
}

Michael Tsokos

Accepted: 20 April 2012/Published online: 22 May 2012

(C) Springer Science+Business Media, LLC 2012

Prahlow's and Byard's "Atlas of Forensic Pathology" is what the title implies-a compilation of remarkable photographs accompanied by a short text. This atlas, with more than 2,500 color photographs reflects forensic pathology as an incredibly visual discipline.

Both authors have decades of autopsy experience and are well-recognized international experts in the field.

This impressive book aims primarily at those professionals who interact with forensic pathologists, e.g. lawyers, prosecutors, police officers and all those others involved in death investigation. However, there are some chapters of this book that are of interest to forensic pathologists too, for example chapter 13 (Gunshot Wound Deaths) and chapter 21 (Miscellaneous), the latter giving interesting photographic examples of snake bite marks, injuries due to animal attacks, and artifacts only rarely seen in autopsy practice.

The 21 chapters are laid out in logical order starting with three introductory chapters, followed by Death Investigation,
Death Certification, Overview of Anatomy and Physiology, The Forensic Examination and Autopsy, Postmortem Changes and Time of Death, Identification of Human Remains, and Natural Deaths, then followed by 10 chapters devoted to the different types of non-natural/violent deaths and ending with Miscellaneous. While the level of detail of the photographs is high, the level of detail of the text in the figure legends is moderate. Occasional histology photographs as well as X-ray pictures add to the style of this atlas.

Throughout the book there are only a few references given at the end of each chapter but more references would have been outside the scope of an atlas.

Prahlow's and Byard's "Atlas of Forensic Pathology" is a highly competent book that performs its intended function very well. Anyone involved in death scene investigation whose primary background is not medical will find this book useful and relevant.
M. Tsokos $(\bowtie)$

Institute of Legal Medicine and Forensic Sciences,

Charité-Universitätsmedizin Berlin, Turmstr. 21 (Haus N),

10559 Berlin, Germany

e-mail: mtsokos@web.de 